\title{
Comparative study between SD BIOLINE Malaria Ag pf rapid diagnostic test and calibrated thick smear in the east region of Cameroon
}

\author{
Agokeng D. Sylvie', Mogou R. Amandine, Ottop F. Manyi ${ }^{3}$, Assob N. Clement \\ ${ }^{1,3}$ University of Buea \\ ${ }^{2}$ Fondation Dr YELE BERTOUA
}

\begin{abstract}
In children of less than 59 months, Malaria is a public health problem, associated with an increased risk of mortality and morbidity. Thus, to improve the quality of the biological diagnosis of malaria, we made a comparative study for results of malaria test using the detection antigen Histidine rich protein II (HRP2) by SD BIOLINE and calibrated thick smear.

As participants, 204 patients admitted at the Bertoua regional hospital were included, biological diagnosis was based on the staining of calibrated thick smear and rapid diagnostic test (RDT) by SD BIOLINE Malaria Ag pf.

The results of this study showed a good performance of the RDT SD BIOLINE Malaria Ag pf, $29(14.21 \%)$ were RDT positive versus 32(15.68\%) for calibrated thick smear. The sensitivity, specificity, positive and negative predictive values of RDT compared to the calibrated thick smear were respectively $(87.5 \%, 99.41 \%, 97.71 \%, 96.55 \%)$ the limitations of RDT were shown with low parasitaemia. The case of false positive were noted in a patient who took drugs without prescription. At the end of our study, we suggested continuous use of RDTs in health centres to strengthen microscopy, which has a long analysis time and to strengthen the staff's ability in management of malaria cases.
\end{abstract}

Keywords: Malaria, RDT, children, parasitaemia, sensitivity, specificity, Thick smear

\section{Introduction}

Malaria is one of the most prevalent and harmful diseases of tropical countries. The WHO in 2005 estimates that more than 2 billion people were exposed worldwide, $25 \%$ of them being in sub-Saharan Africa (1). According to UNICEF's core actions, malaria kills 300 to 500 million people each year and kills more than 1 million children under the age of 5. Children living in sub-Saharan Africa pay the heaviest price for the disease: nearly 300 die each day (2). In Africa, malaria accounts for about $20 \%$ of all child deaths; some children are victims of an acute attack of cerebral malaria that causes rapid coma and death. Children under 5 years old are an integral part of the most vulnerable people affected by this pathology because of their weak immune system (3). During our training and clinical courses, we were struck by the recrudescence of this pathology in children under 5years and we found that the biological diagnosis can be done by several methods. With this in mind, we thought necessary to carry out a study to compare a commonly used Rapid Diagnostic Malaria Test and the Calibrated thick smear in children of 0 to 59 months attending the Regional Hospital of Bertoua. In general, our work will revolve around the improvement of the care thanks to the different performances of the two tests, in order to reduce the morbidity and mortality rate of malaria in these children.

\section{Methodology}

The data collection took place over a month, from the $01^{\text {st }}$ November to 02 December 2018.

The data were collected using a questionnaire designed according to the objectives we wanted to achieve. This study involved the participation of 204 children. 
2 drops of blood at least were collected, $5 \mu$ placed on the SD BIOLINE RDT and $50 \mu 1$ on a clean slide for thick smear. After sucking the slide in distilled water, each slide was stained with Giemsa 10\% and read under a microscope at 100x. Parasitaemia can be estimated here as a percentage of parasites counted in relation to the white blood cell (8000 average).

Data collected were computed and analyzed using Ms. Excel 2013, SPSS 20.0. Significant difference was considered for $\mathrm{P}$ value less than 0.05 .

\section{Results And Discussion}

This comparative study of the SD BIOLINE Malaria Ag Pf with the calibrated thick smear is the first conducted in Bertoua in the Eastern region, it nevertheless follows the one conducted by Sayang et al 2009 in Yaounde (4) who compared the Diaspot -Malaria-Pf with thick smear in a pediatric population, Dogmo et al 2012 in Bafoussam (5) and Akadiri et al (2016) in Abomey on the performance of SD B IOLINE Malaria Ag Pf compared to thcik smear (6).

\section{Sociodemographic characteristics of our study population study population.}

In this study, $56.37 \%(n=115)$ of the subjects were female versus $43.62 \%(n=89)$ males; a sex ratio (male / female) of 0.77. In contrast to a similar study done by Amos in 2005 (7) in Mali or the sex ratio (M / F) was 1.05. Bechem et al in 1999 (8) and Wanji et al in 2008 (9) observed in their study a greater feminine representativeness. The most represented age group was 0-12 months with $58.33 \%$, while the least represented was $49-59$ months with $5.8 \%(n=12)$. This representativeness of the age group could be explained by the fact that parents would be more forced to bring them at the onset of symptoms in consultation, however, they preferred to turn to other solutions (self-medication, indigenous potions ...) for the older ones.

\section{Prevalence of malaria in our study population.}

Remember that our study population consisted only of suspected cases of malaria coming to the laboratory for a confirmatory diagnosis. This is the hospital prevalence.

Table I: Malaria results for each diagnostic test

\begin{tabular}{|ll|ll|l|}
\multirow{2}{*}{ Results } & RDT & \multicolumn{5}{c|}{ Calibrated thick smear } \\
\cline { 2 - 6 } & Number $(\mathbf{n})$ & $\begin{array}{l}\text { Frequency } \\
(\boldsymbol{\%})\end{array}$ & $\mathbf{n}$ & \% \\
\hline POSITIF & 29 & 14,21 & 32 & 15,68 \\
\hline NEGATIF & 175 & 85,78 & 172 & 84,31 \\
\hline TOTAL & 204 & 100 & 204 & 100 \\
\hline
\end{tabular}

Indeed, we know that the majority of malaria cases in Africa do not reach the hospital for various reasons (1). In the end, 32 cases of malaria were confirmed by the calibrated thick smear with a prevalence of 15.68\%, while SD BIOLINE Malaria Ag Pf confirmed 29 cases, i.e a prevalence of 14.21\% (Table I). Considering the calibrated thick smear as a reference, the true prevalence was $15.68 \%$. That is to say that 172 people would have had negative parasitaemia despite the clinical presumption.

Individuals who would followed abusively artemisinin-based combination therapy ( ACT) and whose real diagnosis would be delayed if based on consultation symptoms as stated by Shillcut et al, 2007 (10),WHO 2008 (11). As a reference test, we considered that the specificity of the thick smear was by definition absolute. This reference is valid as regards the comparison with RDT (WHO, 2008). It can be discussed to confirm the diagnosis of malaria, due to the existence of asymptomatic P. falciparum carriers (12).

Comparison of the two diagnostic methods (Calibrated thick smear and SD BIOLINE Malaria Ag Pf).

The two diagnostic methods do not exploit the same characteristics of Plasmodium. One used microscopic observation of the morphological characteristics of the plasmodium and the other (RDT) detected HRP2 by immuno-chromatographic reaction, this Antigen released during the development of P. 
falciparum is specific. Calibrated Thick smear also makes it possible to estimate parasitaemia with relative accuracy.

Concerning associations between the results of biological and each of the 5 main symptoms of the malaria, our study showed that the febrile state was associated neither with the calibrated thick smear nor with RDT. And yet fever was and has always been considered as a major sign of malaria but we found no significant difference between children with and without fever, this allows us to understand that the diagnosis of this disease cannot be based on this single sign, even if it is a sign of major one. Especially since fever is common to many other pathologies in our context $(1,13,14)$. It is the same for the other signs. But associating fever, chills and others we multiply chances to reduce misdiagnosis.

Table II: comparison of RDT and calibrated thick smear

\begin{tabular}{|l|l|l|l|}
\hline \multicolumn{1}{|c|}{$\begin{array}{l}\text { Calibrated } \\
\text { thick smear }\end{array}$} & Positive & Negative & Total \\
\hline Positif & $28(13,72 \%)$ & $4(1,96 \%)$ & \\
\hline Négatif & $1(0,49 \%)$ & $171(83,82 \%)$ & $32(15,68 \%)$ \\
\hline Total & $29(14,21 \%)$ & $175(85,78 \%)$ & $204(100 \%)$ \\
\hline
\end{tabular}

\section{SD BIOLINE Malaria Ag Pf Diagnostic Performance Versus calibrated thick smear}

The sensitivity and specificity of RDT in our study were $87.5 \%$ and $99.41 \%$, respectively.

In view of the work done on the performance of RDT, we found that the sensitivity found in our study is lower than that found by other authors. Thus, Davou Denise in 2011 (15) in Parakou reported a sensitivity of $95.5 \%$, that of Hounto et al in 2013 in Cotonou, is $96.3 \%$ (16) and that of 94.7 reported by Dongmo Tanke Norbert in 2012 in Cameroon with Diaspot®-Malaria-Pf, an assay also detecting HRP2 protein (5).

As for specificity, it is $99.41 \%$. This value obtained in our study is higher than that reported by Hounto et al in 2013 in Cotonou, which found 96.7\%. (16)

Our results revealed 1 case of false positive that is $0.49 \%$. This rate is lower than that found by Houessou M. Clarisse at the HIA / CHU-Parakou and CHUZ Boko in 2015 which was $17.1 \%$ with 34 cases of false positive and the report presented by WHO in 2009 with 4\%. In our study, we assumed that the false positive came from a patients who was collected probably after prior treatment with antimalarial drugs before their admission in the hospital. These false positive cases may be due to the persistence of the HRP2 protein in the blood as several authors have recognized (18).

Table III: RDT SD BIOLINE Malaria Ag Pf and parasitaemia

\begin{tabular}{|llll|}
\hline Parasitaemia & $\begin{array}{l}\text { Calibarted thick } \\
\text { smear postive }\end{array}$ & RDT positive & Sensitivity \\
\hline $\mathbf{1}$ à $\mathbf{5 0}$ & 3 & 0 & - \\
\hline $\mathbf{5 1}$ à $\mathbf{1 0 0}$ & 5 & 5 & $100 \%$ \\
\hline
\end{tabular}




\begin{tabular}{|lccc|}
\hline $\mathbf{1 0 1}$ à 500 & 7 & 7 & $100 \%$ \\
\hline $\mathbf{5 0 1}$ à $\mathbf{1 0 0 0}$ & 8 & 8 & $100 \%$ \\
\hline$\geq \mathbf{1 0 0 0}$ & 9 & 9 & $100 \%$ \\
\hline TOTAL & 32 & 29 & \\
\hline
\end{tabular}

Of a total of 32 confirmed positive samples, 29 were SD BIOLINE Malaria P.f rapid test positive. The study revealed 4 cases of false negative, $1.96 \%$. This value is lower than that found by Davou Denise, which was $3.6 \%$ in her work carried out in Parakou in 2011. The distribution of the sensitivity of RDT in relation with parasitaemia enabled us to observe that the cases of false negatives correspond to cases of low parasitaemia. It thus appears that RDT has a low capacity to detect the disease in case of low parasitaemia as notified by the WHO in its detection threshold indicated in the results of product evaluations, i.e 200 parasites $/ \mu 1$ of blood as indicated in WHO 2012 report(19).

\section{Table VI: Sensitivity and specificity for RDT}

\begin{tabular}{|lll|}
\hline RDT & Disease & No disease \\
\hline Positive & 28(true positve) & 1 (false positive) \\
\hline Negatifve & 4(false negative) & 171 (true negative) \\
\hline
\end{tabular}

\section{Conclusion}

At the end of our work, we note that the effectiveness of the treatment prescribed by the doctor depends largely on the result provided by the laboratory. The effectiveness of RDTs has limitations because of its inability to determine the parasitaemia of a patient. The purpose of this study was to compare the results of SD BIOLINE Malaria Ag Pf with that of calibrated thick smear in the diagnosis of malaria. Our study showed that the RDT SD BIOLINE Malaria used, has a good performance in the diagnosis of Plasmodium infection. In general, the level of performance was considered good because it can diagnose 9 out of 10 cases among patients suspected of malaria. Therefore, we encourage the use of these RDTs in all peripheral health centers and referral health facilities to facilitate early decision-making. However, the use of these tests must necessarily be coupled to microscopy in these reference centers to ensure good management.

ACKNOWLEDGEMENT: To all the staff of the Bertoua regional hospital for their availability.

\section{REFERENCES}

[1] OMS : Document d'orientation de sante publique ouvrage, MSP 2003 Page:675

[2] OMS/UNICEEF: Action essentiel pour l'Unicef ouvrage MSP 2005 Page:13.

[3] OMS: Rapport sur la santé dans le monde 2013, page:26

[4] Samuel Shillcutt et al., Cost-effectiveness of malaria diagnosis methods in sub- saharan Africa in an era of combination therapy ; bulletin of OMS 2007 Article ID :07-042259.

[5] T. N. Dongmo, étude comparative d'un test de diagnostic rapide du paludisme (TDR) avec la goutte d'épaisse à l'hôpital Régional de Bafoussam Cameroun, mémoire online 2012.

[6] Ziyadat Akari et al : " performances diagnostiques de la goutte épaisse et du TDR SD Bioline Malaria en milieu Pédiatrique du CHUZ/Abomey-Calvain. Benin, 2016.

[7] Amos F., performance diagnostique du test rapide optimal II : place de la biologie moleculaire dans l'évaluation du polymorphisme génétique de la lactate déshydrogénases(LDH)de p.falciparum. Thèse de doctorat en pharmacie, unversité de Bamako,Mali 2005 144P.

[8] Bechem N. et al :Evaluation of a rapid test for histidine rich protein2(HRP2) for diagnosis of $\mathrm{pf}$ infection in cameroonian children 1999,93-46

[9] Wandji S. et al.,performance and usefulness of hexagon rapid diagnosis test in children with asymptomatic malaria living in the mount cameroon region, malaria journal, $7: 89$ 
[10] Sayang C., use for HRP2 based rapid diagnosis test for malaria by health personnel during routine consultation out patients in a periperal health facility in yde .2009.82(21343-347).

[11] WHO :Malaria Rapid diagnosis test performance resultof WHO produit testing of malaria :Round1 2008

[12] Munier A. et al : Evaluation d'un test de diagnostic rapide du paludisme dans les zones rurales au Senegal, 2009 Med trop ;69:496-500.

[13] Manirakiza Alexandre et al : utilisation du test de diagnostic rapide en consultation prénatale dans le cadre du traitement antipaludique à Bangui(RCA), 2012

[14] ANOFEL : Association Nationale(Française) de parasitologie, mycologie collection référence ,7é édition Ange ,France ,2002pp :103-122

[15] D. Davou «Etude comparative des résultats de la goutte épaisse et du test de diagnostic rapide (SD BIOLINE Malaria $P . f$ ) et de la microscopie dans le diagnostic biologique du Paludisme au CHDU-B et CS de KPEBIE à Parakou».

[16] A.O.Hountou et al : évaluation d'un test de diagnostic rapide et d'un microscope à fluorescence portable pour diagnostic du paludisme à Cotonou, Benin, Bull. Soc. Pathol. Exot. (2013) 106:2731

[17] Kyabayinze et al,Placental Plasmodium falciparum malaria infection: Operational accuracy of HRP2 rapid diagnostic tests in a malaria endemic setting, Malaria Journal 2011,10:306

[18] Aubry P. et Jaffar-Bendje M.C :Le paludisme ouvrage ,2010 pp6

[19] The World Malaria Report 2012. 